\title{
Comunicação
}

[Communication]

\section{Proteinograma sérico de bezerros recém-nascidos da raça Holandesa obtido por eletroforese em gel de poliacrilamida}

\author{
[Serum protein concentration in newborn Holstein calves determined by means of sodium \\ dodecyl sulphate-polyacrylamide gel electrophoresis] \\ J.J. Fagliari ${ }^{1}$, F.W. Rizolli ${ }^{2}$, S.L. Silva ${ }^{3}$, D.G. Silva ${ }^{3}$ \\ ${ }^{1}$ Faculdade de Ciências Agrárias e Veterinárias - UNESP \\ Via de Acesso Prof. Paulo Donato Castellane, s/n \\ 14884-900 - Jaboticabal, SP \\ ${ }^{2}$ Médica veterinária autônoma \\ ${ }^{3}$ Aluno de pós-graduação - FCAV - UNESP - Jaboticabal, SP
}

O fracionamento eletroforético representa um dos mais confiáveis métodos de identificação de proteínas sangüíneas. As técnicas de eletroforese mais utilizadas em medicina veterinária têm como matrizes fitas de acetato de celulose (Fagliari et al., 1988; Borges et al., 2001) ou filmes de agarose (Keay e Doxey, 1982) e permitem o fracionamento de apenas cinco a sete grupos de proteínas. Gordon (1995) relatou que a técnica de eletroforese em gel de acrilamida contendo dodecil sulfato de sódio (SDS-PAGE) é relativamente simples e de baixo custo, possibilitando a visualização de concentrações séricas extremamente baixas e a identificação de várias proteínas.

O emprego da técnica SDS-PAGE em medicina veterinária pode ser útil na avaliação da cinética das proteínas de fase aguda da resposta inflamatória, facilitando a definição do diagnóstico das doenças animais, como pneumonia de bezerros causada por Mannheimia (Pasteurella) haemolytica (Fagliari et al., 2003), e o prognóstico de intercorrências no período pós-operatório (Fagliari e Silva, 2002). Adicionalmente, é possível identificar e quantificar imunoglobulinas, especialmente em recém-nascidos, orientando o manejo de animais hipogamaglobulinêmicos. Especificamente em bezerros neonatos, cuja permeabilidade intestinal às imunoglobulinas colostrais persiste durante, no máximo, 48 horas após o nascimento (Abel
Francisco e Quigley, 1993), há alta prevalência de falha na transferência de imunidade secundária à inadequada ingestão de colostro (Weaver et al., 2000), chegando tal distúrbio a acometer $40 \%$ dos bezerros (Barragry, 1997). A imunoglobulina $G$ é considerada a mais importante na imunização passiva de bezerros (Menanteau-Horta, 1985).

Perino et al. (1993) consideram falha na transferência de imunidade passiva quando o bezerro apresenta proteinemia total inferior a 4,2g/dl, 48 horas após o nascimento. Após esse período, teores séricos de imunoglobulinas ao redor de $1,7 \mathrm{~g} / \mathrm{dl}$ protegem os neonatos (Adams et al., 1993).

O objetivo deste trabalho foi estabelecer o proteinograma sérico de bezerros recém-nascidos da raça Holandesa, utilizando-se a técnica de eletroforese em gel de poliacrilamida contendo dodecil sulfato de sódio (SDS-PAGE), de modo a propiciar método alternativo para estudo das frações protéicas de neonatos.

Foram examinadas amostras de soro sangüíneo de 40 bezerros recém-nascidos da raça Holandesa, obtidas 48 horas após o nascimento. Os neonatos receberam, em mamadeira, três litros de colostro das próprias mães nas primeiras duas horas após o nascimento e, a partir daí, o volume correspondente a $10 \%$ do peso 
corporal/dia, em três mamadas, com intervalos de oito horas, até completarem 48 horas após o nascimento.

A concentração sérica de proteína total foi determinada pelo método do biureto, utilizandose conjunto de reagentes comercial ${ }^{1}$ e leitura da amostra em espectrofotômetro ${ }^{2}$. Para o fracionamento das proteínas séricas, utilizou-se a técnica de eletroforese em gel de poliacrilamida contendo dodecil sulfato de sódio (SDS-PAGE), proposta por Weber e Osborn (1969). A leitura das frações protéicas foi realizada em videodensitômetro ${ }^{3}$. As proteínas foram identificadas comparando sua mobilidade eletroforética com a de marcador ${ }^{4}$ com pesos moleculares de 28.000 dáltons (D), 45.000 D, $66.000 \mathrm{D}, 97.400 \mathrm{D}, 116.000 \mathrm{D}$ e $205.000 \mathrm{D}$ e das proteínas purificadas ${ }^{4}$ albumina, transferrina, ceruloplasmina, $\alpha_{1}$-antitripsina, haptoglobina e imunoglobulina $\mathrm{G}$.

Para as análises estatísticas, utilizou-se o Statistical Analysis System (User's... 1995). Quando houve diferença significativa entre os proteinogramas, aplicou-se o teste Tukey para a comparação das médias.

Os teores séricos de proteína total foram similares entre os grupos e variaram de $6,82 \pm 1,07 \mathrm{~g} / \mathrm{dl}$ a $7,26 \pm 1,21 \mathrm{~g} / \mathrm{dl}$; portanto, superiores ao valor de $4,2 \mathrm{~g} / \mathrm{dl}$, citado por Perino et al. (1993) como limite mínimo necessário à proteção do recém-nascido. Embora não tenha ocorrido diferença significativa entre os teores séricos de proteína total, a análise dos proteinogramas dos 40 bezerros, 48 horas após o nascimento e após o fornecimento de colostro, revelou a existência de três padrões de traçado eletroforético, denominados proteinogramas padrões 1, 2 e 3 (Tab. 1). A constatação de diferenças quali e quantitativas das frações protéicas em bezerros de uma mesma propriedade, submetidos ao mesmo tipo de manejo, inclusive alimentar, indica que a seleção de grupos experimentais para pesquisas dessa natureza deve levar em conta tal fato, evitando risco de considerar tal característica físiológica como influência de tratamentos experimentais.

\footnotetext{
${ }^{1}$ Labtest, Belo Horizonte, MG

${ }^{2}$ Labquest-Labtest, Belo Horizonte, $\mathrm{MG}$

${ }^{3}$ Shimadzu CS9000, Shimadzu Corp., Kyoto, Japan

${ }^{4}$ Sigma Chemical Co., Saint Louis, MO, USA
}

Dos 40 bezerros examinados, 19 (47,5\%) apresentaram proteinograma padrão 1 , no qual foram observadas 14 proteínas, cujos pesos moleculares (PM) variaram de $28.000 \mathrm{D}$ a 170.000 D. A partir da metodologia utilizada, foi possível identificar oito delas: imunoglobulina $\mathrm{A}$ $(\mathrm{PM}=139.000 \mathrm{D})$, ceruloplasmina $(\mathrm{PM}=125.000$ D), fosforilase $(\mathrm{PM}=92.000 \mathrm{D})$, transferrina $(\mathrm{PM}=79.000 \quad \mathrm{D}), \quad$ albumina $(69.000 \quad \mathrm{D})$, haptoglobina $(\mathrm{PM}=45.000 \mathrm{D})$, glicoproteína ácida $(P M=40.000 \quad \mathrm{D})$ e imunoglobulina $G$ $(\mathrm{PM}=32.000 \mathrm{D})$. As outras seis proteínas não identificadas apresentaram pesos moleculares de $170.000 \mathrm{D}, 58.000 \mathrm{D}, 42.000 \mathrm{D}, 37.000 \mathrm{D}, 35.000 \mathrm{D}$ e 28.000 D. Onze bezerros $(27,5 \%)$ apresentaram proteinograma padrão 2 , também com 14 proteínas, porém com pesos moleculares que variaram de $18.000 \mathrm{D}$ a $170.000 \mathrm{D}$. Foi possível identificar 10 delas: imunoglobulina A, ceruloplasmina, fosforilase, transferrina, albumina, $\alpha_{1}$-antitripsina $(P M=62.000 \quad \mathrm{D})$, haptoglobina, glicoproteína ácida, imunoglobulina $\mathrm{G}$ e hemoglobina (18.000 D). As quatro proteínas não identificadas tinham pesos moleculares de $170.000 \mathrm{D}, 58.000 \mathrm{D}, 35.000 \mathrm{D}$ e 28.000 D. Um terceiro padrão de traçado eletroforético, proteinograma padrão 3, foi constatado em 10 bezerros $(25,0 \%)$. Foram detectadas 12 frações protéicas, cujos pesos moleculares variaram de $28.000 \mathrm{D}$ a $170.000 \mathrm{D}$. Foi possível a identificação de sete delas: imunoglobulina A, fosforilase, transferrina, albumina, haptoglobina, glicoproteína ácida e imunoglobulina G. As cinco proteínas não identificadas apresentaram pesos moleculares de $170.000 \mathrm{D}, 58.000 \mathrm{D}, 42.000 \mathrm{D}, 35.000 \mathrm{D}$ e 28.000 D. Dentre as principais diferenças constatadas nos três proteinogramas, destacam-se: os teores significativamente superiores de ceruloplasmina e de proteína com PM 28.000 D no proteinograma 1, em relação aos outros dois, e a presença da proteína com PM 37.000 D apenas nesse padrão de proteinograma; a presença da fração $\alpha_{1^{-}}$ antitripsina somente no proteinograma $2 \mathrm{e}$, nesse padrão, o valor significativamente menor da proteína com $58.000 \mathrm{D}$ em relação aos demais padrões e a ausência das frações com PM 42.000 $\mathrm{D}$ e $37.000 \mathrm{D}$; e os teores significativamente maiores de IgA e da proteína com PM 58.000 D e menores de transferrina, haptoglobina e glicoproteína ácida. Possivelmente, a fração hemoglobina detectada no proteinograma padrão 2 deve-se à hemólise da amostra, imperceptível ao exame visual de rotina. 
Tabela 1. Média e desvio-padrão dos valores das frações protéicas $(\mathrm{mg} / \mathrm{dl})$ de três proteinogramas de bezerros da raça Holandesa, 48 horas após o nascimento, obtidos em gel de poliacrilamida contendo dodecil sulfato de sódio

\begin{tabular}{lcccc}
\hline Proteína total e frações & $\begin{array}{c}\text { Peso molecular } \\
\text { (dáltons) }\end{array}$ & $\begin{array}{c}\text { Proteinograma } 1 \\
(\mathrm{n}=19)\end{array}$ & $\begin{array}{c}\text { Proteinograma } 2 \\
(\mathrm{n}=11)\end{array}$ & $\begin{array}{c}\text { Proteinograma } 3 \\
(\mathrm{n}=10)\end{array}$ \\
\hline Proteína total $(\mathrm{g} / \mathrm{dl})$ & & $6,82 \pm 1,07 \mathrm{a}$ & $7,26 \pm 1,21 \mathrm{a}$ & $6,94 \pm 0,96 \mathrm{a}$ \\
Não identificada & 170.000 & $108,26 \pm 66,17 \mathrm{a}$ & $116,42 \pm 70,23 \mathrm{a}$ & $142,61 \pm 76,18 \mathrm{a}$ \\
Imunoglobulina A & 139.000 & $273,60 \pm 33,48 \mathrm{a}$ & $262,11 \pm 26,31 \mathrm{a}$ & $\begin{array}{c}409,86 \pm 50,61 \mathrm{~b} \\
\text { não detectada }\end{array}$ \\
Ceruloplasmina & 125.000 & $40,37 \pm 20,18 \mathrm{a}$ & $22,46 \pm 9,08 \mathrm{~b}$ & $29,64 \pm 10,84 \mathrm{~b}$ \\
Fosforilase & 92.000 & $33,94 \pm 19,71 \mathrm{ab}$ & $43,64 \pm 20,62 \mathrm{a}$ & $106,39 \pm 42,13 \mathrm{c}$ \\
Transferrina & 79.000 & $388,67 \pm 36,34 \mathrm{a}$ & $293,04 \pm 33,12 \mathrm{~b}$ & $2.703,98 \pm 296,71 \mathrm{a}$ \\
Albumina & 69.000 & $2.903,18 \pm 321,49 \mathrm{a}$ & $2.801,31 \pm 304,10 \mathrm{a}$ & não detectada \\
$\alpha_{1}$-antitripsina & 62.000 & não detectada & $14,37 \pm 10,61$ & $911,31 \pm 98,96 \mathrm{c}$ \\
Não identificada & 58.000 & $789,12 \pm 76,30 \mathrm{a}$ & $581,75 \pm 60,43 \mathrm{~b}$ & $53,12 \pm 9,31 \mathrm{~b}$ \\
Haptoglobina & 45.000 & $76,21 \pm 12,33 \mathrm{a}$ & $87,36 \pm 11,98 \mathrm{a}$ & $29,41 \pm 16,64 \mathrm{~b}$ \\
Não identificada & 42.000 & $56,64 \pm 10,73 \mathrm{a}$ & não detectada & $15,27 \pm 10,73 \mathrm{~b}$ \\
Glicoproteína ácida & 40.000 & $26,17 \pm 12,07 \mathrm{a}$ & $30,08 \pm 13,17 \mathrm{a}$ & não detectada \\
Não identificada & 37.000 & $29,40 \pm 16,32$ & não detectada & $39,66 \pm 20,46 \mathrm{~b}$ \\
Não identificada & 35.000 & $18,28 \pm 9,62 \mathrm{a}$ & $28,14 \pm 15,11 \mathrm{ab}$ & $1.801,96 \pm 297,43 \mathrm{a}$ \\
Imunoglobulina G & 32.000 & $1.869,07 \pm 303,61 \mathrm{a}$ & $1.965,62 \pm 238,41 \mathrm{a}$ & $544,12 \pm 48,67 \mathrm{c}$ \\
Não identificada & 28.000 & $130,43 \pm 17,67 \mathrm{a}$ & $632,04 \pm 58,38 \mathrm{~b}$ & não detectada \\
Hemoglobina & 18.000 & não detectada & $149,17 \pm 43,97$ &
\end{tabular}

Portanto, o proteinograma obtido em gel de poliacrilamida contendo SDS-PAGE possibilitou a detecção de até 14 proteínas no traçado eletroforético de bezerros recém-nascidos da raça Holandesa, 48 horas após o nascimento. Proteinogramas obtidos em gel de agarose e em fitas de acetato de celulose (Keay e Doxey, 1982; Fagliari et al., 1988; Borges et al., 2001), comumente utilizados na prática veterinária, permitiram a detecção de cinco a sete grupos de proteínas. Pode-se considerar que a grande vantagem do uso da técnica SDS-PAGE, em relação às demais técnicas de eletroforese, é a possibilidade de identificação de maior número de proteínas específicas, em especial imunoglobulina $\mathrm{G}$ e proteínas de fase aguda, como ceruloplasmina, $\alpha_{1}$-antitripsina, transferrina, haptoglobina e glicoproteína ácida. Enquanto a concentração sérica de imunoglobulina $G$ permite avaliar a imunidade do recém-nascido (Menateau-Horta, 1985;
Adams et al., 1993; Barragry, 1997; Fagliari e Silva, 2002; Fagliari et al., 2003), as proteínas de fase aguda auxiliam no diagnóstico precoce e no prognóstico de enfermidades inflamatórias, tão comuns em neonatos.

Concluindo, pode-se considerar que a técnica SDS-PAGE, para fracionamento de proteínas do soro sangüíneo, pode ser útil como método auxiliar de avaliação da imunidade passiva e de diagnóstico e prognóstico de doenças em bezerros neonatos. No entanto, devem-se considerar as diferenças fisiológicas, possivelmente decorrentes de influência genética, entre os proteinogramas de bezerros recém-nascidos, evitando-se risco de interpretação incorreta dos resultados.

Palavras-chave: bezerro, proteinograma, eletroforese, SDS-PAGE

\begin{abstract}
The serum protein concentration of newborn Holstein calves determined by means of sodium dodecyl sulphate-polyacrylamide (SDS-PAGE) was studied. Blood samples from 40 healthy newborn calves were obtained 48 hours after birth. Calves had been given 3 liters of colostrum within 2 hours after birth, following by dose corresponding by 15\% of animal weight each 24 hours. The results showed three
\end{abstract}


different proteinograms: 19 calves had 14 proteins with molecular weights $(M W)$ ranging from 28,000 D to $170,000 D$ (proteinogram 1); 11 calves had 14 proteins with $M W$ ranging from 18,000 to 170,000 D (proteinogram 1); and 10 calves had 12 proteins with $M W$ ranging from 28,000 D to 170,000 D (proteinogram 3). The three groups presented similar IgG levels. The highest serum concentration of ceruloplasmin were verified in proteinogram 3, which had the lowest serum level of protein with MW $58,000 D$. It was verified $\alpha_{1}$-antitrypsin only in proteinogram 2, which had no proteins with MW of 42,000 $D$ and 37,000D. The highest serum concentrations of IgA and protein with $M W 58,000 \mathrm{D}$, and the lowest serum levels of transferrin, haptoglobin, and acid glycoprotein were verified in proteinogram 3. Measurement of serum protein concentrations by SDS-PAGE may be useful in monitoring the occurrence of hypogammaglobulinemia and the neonatal disease in calves.

Keywords: calf, proteinogram, electrophoresis, SDS-PAGE

\section{REFERÊNCIAS BIBLIOGRÁFICAS}

ABEL FRANCISCO, S.F.; QUIGLEY, J.D. Serum immunoglobulin concentrations after feeding maternal colostrum or maternal plus colostral supplement to dairy calves. Am. J. Vet. Res., v.54, p.1051-1054, 1993.

ADAMS, R.; WHITE, M.O.; WILLIAMS, D.F. et al. Physiologic differences between twin and single born beef calves in the first two days of life. Cornell Vet., v.83, p.13-29, 1993.

BARRAGRY, T. Calf diarrhoea. Practice, v.40, p.49-51, 1997.

BORGES, A.S.; FEITOSA, F.L.F.; BENESI, F.J. et al. Influência da forma de administração e da quantidade fornecida de colostro sobre a concentração de proteína total e de suas frações eletroforétidas no soro sangüíneo de bezerros da raça Holandesa. Arq. Bras. Med. Vet. Zootec., v.53, p.629-634, 2001.

FAGLIARI, J.J.; PASSIPIERI, M.; CURI, P.R. et al. Valores padrões das proteínas séricas de bovinos da raça Guzerá. II. Proteinograma sérico de bezerros recém-nascidos. Ars Vet., v.4, p.225$232,1988$.

FAGLIARI, J.J.; SILVA, S.L. Hemograma e proteinograma plasmático de eqüinos hígidos e de eqüinos acometidos por abdômem agudo, antes e após laparotomia. Arq. Bras. Med. Vet. Zootec., v.54, p.559-567, 2002.

FAGLIARI, J.J.;.WEISS, D.J.; McCLENAHAN, D. et al. Serum protein concentrations in calves with experimentally induced pneumonic pasteurellosis. Arq. Bras. Med. Vet. Zootec., v.55, p.383-387, 2003.

GORDON, A.H. Electrophoresis of proteins in polyacrylamide and starch gels. New York: Elsever Science Publishers, 1975. 213p.

KEAY, G.; DOXEY, D.L. Species characteristics of serum proteins demonstrated after agarose gel electrophoresis. Vet. Res. Commum., n.5, p.263-270, 1982.

MENANTEAU-HORTA, A.M. Effect of maternal antibody upon vaccination with infectious bovine rhinotracheits and bovine virus diarrhoea vaccines. Can. J. Comp. Med., v.49, p.10, 1985 .

PERINO, L.J.; SUTHERLAND, R.L.; WOLLEN, N.E. Serum gammaglutamyltransferase activity and protein concentration at birth and after suckling in calves with adequate and inadequate passive transfer immunoglobulin G. Am. J. Vet. Res., v.54, p.5659, 1993.

USER'S guide: statistics. Version 6.12. Cary:SAS, Institute, 1995.

WEAVER, D.M.; SMITH, C.B.; HONHEY, F.S. Passive transfer of colostral immunoglobulins in calves. J. Vet. Int. Med., v.14, p.569-577, 2000.

WEBER, K.; OSBORN, M. The reability of molecular weight determinations by dodecyl sulfate-polyacrylamide gel electrophoresis. $J$. Biol. Chem., v.244, p.4406-4412, 1969. 